\title{
EDITORIAL
}

\section{LA FUNDACIÓN DE LA UNIVERSIDAD PERUANA CAYETANO HEREDIA 1961-2011}

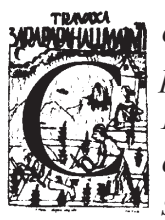
orría el final de la quinta década del siglo pasado y en la Universidad Nacional Mayor de San Marcos se desarrollaba un conflicto, de larga data entre la Universidad, a través de su Rector, Luis Alberto Sánchez, y la Facultad de Medicina de San Fernando, representada por su Decano Alberto Hurtado Abadía. El enfrentamiento entre la Universidad y su Facultad de Medicina tenía trasfondos políticos, académicos, demagógicos, pedagógicos y espirituales que, para cada una de las partes, adquirían un significado diverso según los múltiples puntos de vista. Cada posición esgrimía planteamientos que se consideraban como lo que mejor convenía para la adecuada marcha de los estudios en general y de los de medicina en particular. La instauración del Cogobierno del Tercio Estudiantil en los consejos universitarios era uno de los puntos más críticos: para los unos la participación de los alumnos significaba un aporte de juventud en el manejo de la Institución, se cumplía así uno de los anhelos del movimiento de Reforma Universitaria. Para los otros el movimiento de Reforma no traería ninguna ventaja académica a la Facultad de Medicina ya que el tercio estudiantil dificultaría la toma de decisiones técnicas, adecuadas a la indole de los estudios médicos y a la formación profesional lo que, entre otras consecuencias, pondría en entredicho el adecuado, ponderado y maduro ejercicio de la medicina. El clima del conflicto se hizo candente, el componente emocional era cada día mayor, el diálogo podía devenir en polémica: en esa situación se planteó que si la Facultad de Medicina estaba obligada a aceptar el tercio estudiantil, los profesores de la Facultad se verían obligados a renunciar. Es así como, el 25 de julio de 1961, un total de 497 profesores presentaron su renuncia irrevocable, que fue aceptada y se hizo efectiva el 12 de agosto, al Rector de la Universidad.

Pese a los problemas de toda indole que la renuncia pudiera ocasionar en la vida de los renunciantes, particularmente de los profesores a dedicación exclusiva, el ánimo del grupo era de entusiasmo: se sentía que en él estaba la posibilidad de mantener el nivel académico de la enseñanza médica, e incluso de renovarla, para beneficio del país. El espíritu infuso en los renunciantes fue, con el liderazgo de los maestros Honorio Delgado y Alberto Hurtado, el de crear una nueva Universidad Médica. El grupo se reunió en Asamblea del Cuerpo Docente de la Facultad de Medicina el 25 de julio de 1961 y, ante los graves acontecimientos que amenazaban destruir la educación médica del país, acordó ${ }^{\prime}$ :

"1 Constituir la Unión Médica de Docentes Cayetano Heredia, que agrupará a todos los maestros de San Fernando, que sostienen indeclinablemente sus ideales de una auténtica reforma universitaria. $2^{\circ}$ Elegir Presidente de la Institución al ilustre maestro Dr. Honorio Delgado, quien estará asesorado por los Comités que él determine. $3^{\circ}$ Elegir Secretario de la Institución al Dr. Ernesto Ego-Aguirre. $4^{\circ}$ Señalar como local provisorio de la Institución, el de la Academia Nacional de Medicina, cedido en actitud generosa y comprensiva. $5^{\circ}$ Autorizar al Dr. Honorio Delgado para que, en nombre de la "Unión Médica de Docentes Cayetano Heredia", haga conocer a las autoridades nacionales nuestra firme decisión de ofrecer a la colectividad nuestros servicios docentes, dentro de los requisitos indispensables para una enseñanza médica seria y responsable. Fdo. Víctor Alzamora Castro, Hernán Torres, Jorge Voto Bernales y Fernando Porturas".

El 8 de agosto se aprobó el Acta de Fundación de la Unión Médica de Docentes "Cayetano Heredia” y empezaron las acciones y movimientos convenientes, para concretar alguna ayuda, de entidades privadas y obtener así los fondos necesarios para poner en marcha los anhelos creativos, del grupo de docentes, al que se habian adherido alrededor de 250 estudiantes, que querian participar, en lo que fuera conveniente, para lograr lo que

1. Los textos entrecomillados corresponden al libro: "Planteamientos Fundamentales de la Renovación Universitaria", salvo el párrafo que se indica pertenece a Honorio Delgado. 
se conocía como la Auténtica Reforma Universitaria. La trascendencia de la creación de la nueva universidad fue reconocida en el extranjero y se concretó con la ayuda de varias instituciones, particularmente fundaciones de la talla de la Rockefeller y la Kellog.

El 22 de setiembre el Estado Peruano autorizó el funcionamiento de la Universidad Peruana de Ciencias Médicas y Biológicas (que posteriormente, para que ese nombre no restringiera la futura expansión institucional, fue cambiado por el de Universidad Peruana Cayetano Heredia, UPCH). Habiéndose alquilado el local del antiguo Colegio de Belén, la UPCH pudo abrir sus puertas el 15 de enero de 1962 para recibir las solicitudes de los primeros postulantes al ingreso a la flamante casa de estudios. El 16 de marzo se nominaron las autoridades universitarias, siendo elegido Rector el Prof. Honorio Delgado.

El 2 de abril concursaban 538 postulantes para ocupar las 70 vacantes del primer año de estudios universitarios. El 18 de junio se iniciaron las actividades académicas para el primer año de premédicas $y$ los primeros cinco años de medicina. El movimiento de Renovación Universitaria estaba impulsado por un poder espiritual manifiesto y por ello, desde el primer acto público oficial multitudinario, que fue el examen de ingreso a la recién fundada Universidad, tuvo una acogida sorprendentemente alta. La novedad del examen estribó en el hecho que fue la primera vez que se usaron, en la Universidad Peruana, preguntas de selección múltiple, con calificación computarizada. Con ello y las medidas de seguridad adecuadas para evitar filtraciones de preguntas y/o respuestas y falseamiento de los calificativos, se pudo lograr resultados justos e intachables, acordes con la visión ética que subyacía a la fundación de la UPCH.

La conveniencia de contar con un documento, que contuviera los planteamientos fundantes de la Universidad, se cristalizaron el 6 de noviembre de 1964 cuando el Consejo Universitario, “... a propuesta del
Dr. Mariano Querol, acordó se formara una Comisión encargada de redactar lo pertinente a la historia, esencia, significado y proyección de nuestra Institución ... Como resultado de su labor, la Comisión, en junio de 1966, presentó a las autoridades de la Universidad un documento de trabajo que sirvió de base para la nueva estructura de la Universidad Peruana Cayetano Heredia, aprobada en sesión del Consejo Universitario del 7 de marzo de 1967". Ese mismo año, sobre la base de lo anterior se publicó el libro "Planteamientos Fundamentales de la Renovación Universitaria".

Lo anterior pone claramente de manifiesto que la labor llevada a cabo fue ingente para todos los participantes, que no estuvieron animados por fuerzas oscuras sino por la creatividad poética y apasionada, por la fe en el poder de la verdad y de la equidad docentes, que permitía el surgimiento y el refuerzo de la riqueza emocional y humana de los jóvenes estudiantes que abrazaban el movimiento de Renovación Universitaria y que serían, y son, los abanderados de una Universidad que existe en función de valores académicos y que no estuvo, ni está, guiada por ambiciones políticas partidarias ni demagógicas.

El espiritu del grupo, empeñoso en el logro de sus fines, fue de solidaridad y generosidad en la entrega personal, trabajando denodadamente en todas las labores que se requerían, con fe en alcanzar los objetivos, claridad en las metas docentes, infatigable en lo laboral, con desinterés económico y esfuerzo rayanos en el sacrificio y, hay que recalcar, todo ello desplegado sin protagonismo como fue el gesto voluntario y generoso, de muchos docentes renunciantes a no cobrar emolumentos sino, antes bien, aportar sumas mensuales durante largos meses, para subvenir al pago de los profesores a tiempo completo y a dedicación exclusiva. La gestión grupal fue vibrante por el liderazgo espiritual y ético de Honorio Delgado, convertido en acción por el pensamiento pragmático de Alberto Hurtado. La UPCH se generó no como una institución para una élite socioeconómicamente alta, sino como un semillero 
cientifico, cultural, social e individual, enriquecido por la diversidad de intereses y la deslumbrante limpidez valorativa de sus creadores.

Por ello fue muy grato aprehender cómo las fuerzas -sociales, políticas, universitarias y personales-que, antes de la creación de la Universidad Peruana de Ciencias Médicas y Biológicas se mostraron incrédulas, llegaron a apreciar, sin censuras ni críticas, el surgimiento de la UPCH: esta Institución brotó como una antología académica, sorprendentemente, sin oposición, sin ser criticada; más bien puede decirse que, desde el comienzo de su gestión, tuvo el reconocimiento, esperanzado, de un país que anhelaba disponer de una universidad médica de alto nivel.

Procede aquí destacar la avenencia de los profesores para sobrepasar las limitaciones de espacio y medios de la naciente Institución. Esto se solucionó sorprendentemente bien por el ingenio de los docentes para, con los escasos fondos existentes y muchas veces con aportes personales, cubrir la necesidad de equipos que, en los días fundacionales, no existían. En este sentido cabe considerar que, contra todo pronóstico, la creación de la UPCH ha supuesto un milagro financiero surgido de la generosidad de los amantes de la excelencia en la enseñanza y de los que anhelan alcanzar la mejor preparación, sea cual fuere la categoría económica del alumno.

El poder de un grupo de 497 profesionales imbuidos poéticamente de lo que se llamó "mística", han creado una universidad laica, en la que no median fuerzas rastreras ni afanes protagónicos, por una condición anímica anagógica (en el sentido etimológico, de anagogikos: que eleva el espiritu), sin referentes políticos ni religiosos. El resultado es una gesta en la que los gestores son los que conforman el grupo de renunciantes, entre los que se cuenta, grata y dolorosamente, a los que nos dejaron su vida, ejemplar en lo humano y lo pedagógico, como lo fueron: Honorio Delgado, Alberto Hurtado, Victor Alzamora, René Gastelumendi,
Enrique Fernández, Ramiro Castro de la Mata, Javier Mariátegui, Hugo Lumbreras, Keny Tejada, Leopoldo Chiappo (recientemente fallecido). Estos son solo algunos de la lista de los preclaros fundadores de nuestra casa de estudios. Todos ellos seres humanos religados para mantener en alto el estandarte del arte y ciencia de la cultura universitaria y de la medicina.

El presente número de ACTA HEREDIANA muestra la condición psicológica de un grupo humano solidario que funcionó y sigue funcionando, cincuenta años después, como una corporación de maestros, profesores, alumnos y graduados unidos con el propósito de enseñar, aprender e investigar en el hontanar del conocimiento, la vastedad de la cultura, la exquisitez del arte y la plenitud de la espiritualidad.

Es motivo de orgullo, el hecho que la concepción de la UPCH se logró sin tener en cuenta, y ello hubiera podido considerarse un error por omisión, los aspectos económicos y mucho menos los financieros. De resultas de ello la UPCH sigue siendo un bien creciente, sin fines de lucro personal, sin dueños, que deviene en una institución con la ambición puesta en lograr la excelencia de la educación, la investigación cientifica universitarias y el enriquecimiento de la cultura. Todos estos anhelos son valores indefectiblemente nacionales y universales.

La fundación de la UPCH tiene lugar como un movimiento de Renovación Universitaria, en lo cultural, educativo y de investigación de los problemas nacionales. La Reforma Universitaria resalta en lo politico, y es facilista en lo educativo, con claros fines demagógicos. El crecimiento de la UPCH es expresión del afán humanista de la Institución y del interés en el saber y el investigar de sus fundadores y aquellos, maestros y alumnos, que se han incorporado a ella en el curso de 50 años. De ello habla la fundación de las Facultades de Ciencias y Filosofia "Alberto Cazorla Tálleri", de la Facultad de Educación, de la Facultad de Psicología "Leopoldo Chiappo Galli" y del Instituto de Investigaciones de la Altura. 
Es notable y con ribetes de profético que, ya en 1951, Honorio Delgado escribiera “... la concepción cientifico-técnica de las cosas y de la situación del hombre en el cosmos no ofrece al individuo y a la sociedad, aparte de la pura consideración conceptual de lo finito, sino medios para subsistir y mejorar materialmente; de ninguna manera ofrece sentido y fines supremos a la vida del hombre ... la formación espiritual de la persona con el estímulo de la sabiduría clásica es capaz de despertar y desenvolver las mejores disposiciones de su estimativa ... El influjo de las ideas e imágenes de los pensadores de la primavera de la humanidad ... alcanza a la profundidad del ser del hombre no como espiritu eternizado, sino a la manera de la simiente renovadora".

Desde su fundación hasta la fecha, la UPCH ha mantenido vigentes los valores que constituyen su esencial razón de ser: "la esencia de la universidad, es decir su naturaleza, lo permanente e invariable en ella y lo que la distingue de otra cosa, puede ser considerada desde tres puntos de vista fundamentales ... La universidad es un centro para la promoción de la cultura ... La universidad ha de formar a las personas de acuerdo a determinadas normas culturales y éticas, como un fin en sí, sin menoscabo de que aquéllas sirvan, directa o indirectamente, a la colectividad. En la universidad el hombre busca obtener una visión coherente de la realidad... Esencial y teleológicamente, la universidad ha de cumplir una misión formativa, humanística, tendiente al enriquecimiento cultural y al desarrollo integrativo armónico del individuo, que conduzca a la adquisición y al manejo del conocimiento como fundamento de un estilo de vida que le haga profesar, esto es, vivir en libre y leal conformidad con las altas

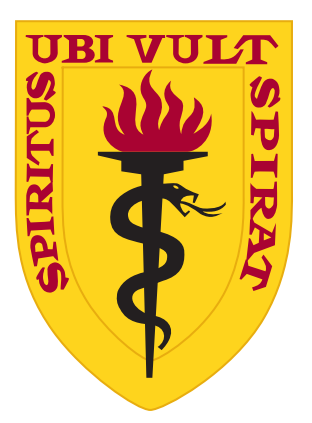

normas éticas que la universidad ofrece. Asi el hombre, al par que enaltece su propia existencia con el conocimiento, se halla en condiciones de utilizarlo en forma mediata o inmediata, directa o indirecta, al servicio de la comunidad social. El arquetipo del individuo, formado en el ámbito de la esencia universitaria, es aquel que alcanza una forma de vida, impecable y plena, en un mundo que se esfuerza por abarcar con unción, merced a su visión sintetizadora y humanística ... la universidad constituye, desde el punto de vista social, una institución corporativa, sin fines de lucro, dimanada de la comunidad social, y por ende, al servicio de la misma ... En suma, la universidad es una institución corporativa, sin fines de lucro, dimanada de la comunidad social, conformada por maestros, alumnos y exalumnos, unidos en un afán espontáneo e indeclinable de aprender, enseñar e investigar. Constituye un centro formativo, humanístico $y$ de servicio a la colectividad para la promoción de la cultura, autónomo en su gobierno y en constante renovación ... lo valioso en nuestra Universidad es su firme propósito de proyectarse como una institución que no desea seguir siendo lo que es hoy, sino testimoniar mañana y siempre, su genuina vocación de grandeza ...".

Los propósitos de los fundadores de la institución que en el curso de 50 años se vienen logrando, pueden resumirse asi: la UPCH “... se convierte en una Universidad en plena y constante renovación, si logra aceptar y preparar un estudiantado maduro destinado a ocupar lugares descollantes en la vida intelectual del pais, si logra excitar la sensibilidad de los pudientes y movilizar la ayuda de las esferas gobernantes, estará logrando a nivel nacional y tal vez a nivel latinoamericano, la plasmación de la Renovación Universitaria”.

MARIANO QUEROL L. Profesor Emérito de la UPCH 